\title{
Research on Smart Mobile Classroom Design from the Perspective of Game Learning - Taking Preschool Education Major of Distance Education as an Example
}

\author{
Li Cheng ${ }^{1, *}$, Li Zhenhua ${ }^{2}$ \\ ${ }^{1}$ Finance and State Asset Management Office, Zhejiang Radio and Television University, Hangzhou, China \\ ${ }^{2}$ Institute of Higher Education, Zhejiang Commercial Vocational and Technical College, Hangzhou, China
}

Email address:

happy992u@163.com (Li Cheng)

${ }^{*}$ Corresponding author

To cite this article:

Li Cheng, Li Zhenhua. Research on Smart Mobile Classroom Design from the Perspective of Game Learning — Taking Preschool Education Major of Distance Education as an Example. Education Journal. Vol. 8, No. 6, 2019, pp. 349-353. doi: 10.11648/j.edu.20190806.27

Received: September 25, 2019; Accepted: November 25, 2019; Published: December 9, 2019

\begin{abstract}
At present, smart mobile classroom is becoming more and more popular, and the research progress of game based learning is constantly promoted, It provides favorable conditions for the combination of game learning and smart mobile classroom. On the basis of defining the concepts of game based learning and smart mobile classroom, the combination of the two is proposed. This paper proposes a framework of smart mobile classroom design in the view of game learning, and takes the English natural spelling course of distance education as an example to realize the design of the framework, and answers the questions of "how to combine the mobile terminal of smart classroom with the game learning classroom" and "how to establish the smart mobile classroom teaching mode based on game learning".
\end{abstract}

Keywords: Game, Smart Classroom, Mobile, Cloud Computing, Distance Education

\section{Introduction}

With the popularization of smart phones and tablets, the rapid development of modern information technology, such as cloud computing, big data, Internet of things, artificial intelligence, etc., human society is moving from the information age to the intelligent age, and intelligent mobile learning has become a hot topic in teaching research. From the "Internet + education" along the way, intelligent learning is an inevitable trend of education development, but also a new paradigm of education. Since the release of "Education Informatization 2.0 Action Plan "in 2018, China has paid more attention to the exploration of the integration of educational technology and curriculum, the teaching and learning methods under the background of educational informatization, and the teaching design of educational informatization. China's education informatization work, especially the reform of teaching methods brought about by the combination of educational technology and learning methods, is more in-depth. Relying on the intelligent learning environment and the educational concept of "teaching for fun", we can promote the emotional exchange between students and teachers [1-2].In the case of intelligent learning becoming more and more common, how to better build the smart mobile classroom in the game environment is particularly important and meaningful. As far as distance open education workers are concerned, it is worth exploring deeply. This paper puts forward the combination of game based learning and smart mobile classroom, and the design framework of smart mobile classroom under the vision of game based learning. Taking the preschool education major of distance education as an example, it completes the teaching implementation process of classroom design, and provides an efficient teaching and learning mode for teachers and students.

\section{Review of Smart Classroom Research}

At present, there are many researches on the design of smart classroom environment and classroom model. TangYiwei and others put forward a design scheme for the 
construction of smart classroom, and verified the design scheme of smart classroom through practical cases in different disciplines. ZhanQinglong and others explained the smart learning activities based on maker education from the aspects of activity space construction and activity implementation. Zhuzhiting first studied the shortcomings of flipped classroom, and then put forward the ways and methods to change to intelligent classroom, and elaborated the creation of intelligent learning space from multiple dimensions. PangJingwen, Lu Cheng, etc. have made relevant research in the practical application of smart classroom, respectively in primary school English and mathematics. Generally speaking, there are few researches on the design and application of smart classroom learning mode [3-4]. ZhengYunxiang, BianJinjin and so on put forward the design reform of intelligent classroom teaching mode one after another, while the latter also explored the personalized learning mode. LiuBangqi carried out a research on the design of "three stages and ten steps" structure model based on smart classroom by comparing the teaching process of smart classroom and traditional classroom [5].

Overseas research on smart classroom mainly includes theoretical research, design research, application research and so on. Timms and Michael J, after recognizing the educational value of artificial intelligence, point out that artificial intelligence will participate in the process of education and teaching, provide auxiliary functions for efficient learning of teachers and students, and provide relevant cases to prove it. Murphy and Cathy see the research hotspot of smart classroom in the future. They mainly elaborate the design attention points, technical support, teacher pre job training and other issues when they are changing to smart classroom. Strauss and Howard expressed their views through "New Learning Space: Smart Learners, Not Smart Classrooms": classroom, laboratory, virtual laboratory and learning skills will be the focus of smart classroom.

In the above research of domestic and foreign scholars, there is less research on the construction of smart classroom in the game learning environment, and less research on the construction of smart mobile classroom. In the new era of mobile learning popularization, it is particularly necessary to study the construction mode of smart mobile classroom in the game learning environment.

\section{Combination of Game Learning and Smart Mobile Classroom}

\subsection{Concept Definition}

\section{(1) Smart mobile classroom}

Smart mobile classroom is a concept extended from smart classroom [6], there is no unified view in the current academic circle. In terms of the essence of its smart mobile classroom, it has built an o2o education and teaching mode with high-efficiency interaction among schools, educators, learners, etc. [7], realizing the "connection" to the classroom center by mobile means. In the smart mobile classroom, learners become the master of learning, carry out active learning, actively explore the classroom learning content with the help of mobile devices, independently arrange the learning time and progress, and actively form a cooperative teaching mechanism of mutual assistance with other learners and educators. Relying on the mobile education technology, we can form the ways and methods of active learning, intelligent teaching, intelligent management, dynamic sharing and dynamic supervision, reshape the education and teaching ecology of intelligent teaching and learning, intelligent management, so as to realize the reconstruction of education and education ecology between teaching and learning, learning and learning, and between schools.

(2) Game learning

In recent years, the popularity of game learning research has been increasing. Taking China CNKI database as an example, it can be found that the research on game based learning has been on the rise since 2003, with 114 papers published in 2018 and 134 papers predicted to be published in 2019. More and more attention has been paid to game learning and flipped classroom teaching, game learning and primary and secondary school teaching, game learning and artificial intelligence. By summarizing the interpretation of game learning by NiuYuxia, Tao Kan and other experts, we understand that game learning is a teaching mode that uses game points, rankings, game badges and other game mechanisms to design teaching activities and practice teaching guidance for learners.

(3) Cloud computing

Cloud computing refers to decomposing huge data processing programs into numerous small programs through the network "cloud", and then processing and analyzing these small programs through a system composed of multiple servers to get results and return them to users. Through cloud computing technology, it can process tens of thousands of data in a few seconds, so as to achieve powerful network services. Through the education cloud, we can virtualize the hardware and resources of education intelligent mobile learning, and then transfer them to the Internet to provide a convenient and quick learning platform for teachers and students.

\subsection{Combination of Game Learning and Smart Mobile Classroom}

Horizon Report, as the vane of global education informatization, plays an important role in guiding the development of education informatization technology and application. It can be found that the horizon report for four consecutive years mentions Gamification in important technologies, turning to analysis technology, artificial intelligence and other technologies from 2016, that is to say, Gamification will realize the integration of technology and education through specific curriculum and teaching reform and gradually realize the landing [9-10]. With the development of mobile technology and the popularity of mobile devices (smart phones, tablet computers, etc.), smart mobile classroom has become popular in the world and become a hot topic of teaching research. Smart mobile 
classroom greatly meets the personalized learning needs of learners. Learners can obtain learning resources through mobile devices and wireless communication networks at any time and any place where they need to learn, form communication and cooperation with other learners or teaching staff, and realize the knowledge construction process between individuals and society.

At present, there are two ways of combination of game and smart mobile classroom: the first is to use game mechanism and game elements to carry out in class teaching activities in smart mobile classroom [11], and stimulate learners' learning interest and motivation through game activities. The second is to acquire knowledge and skills through learners' experience learning in systematic educational games, which is currently only used for partial teaching guidance of some courses due to the high requirements of early development investment and teaching guidance. At present, smart mobile classroom has been widely used in schools, especially in distance education, and achieved good teaching results. At the same time, it can be seen that many teaching design researchers in many countries began to try the combination of game learning and MOOC, so as to eliminate the low participation in MOOC learning process. From the perspective of effectively improving the participation of distance education learners in smart mobile classroom learning, mobile devices are easy to cause learners' lack of focus in classroom learning, skipping some text learning content and other learning behaviors, and also cause the problem of increasing the dropout rate. Therefore, it is necessary to learn from the combination of game based learning and MOOC, and introduce it into the game based learning and smart mobile classroom, so as to improve the low participation of distance education.

\section{Smart Mobile Classroom Design Practice in the Perspective of Game Learning}

\subsection{Design Framework of Smart Mobile Classroom from the Perspective of Game Learning}

Because of the introduction of mobile devices, smart mobile classroom brings changes in teaching objectives, teaching content, teaching design, teaching experience, etc. The teaching content is placed in the education cloud, which provides enough computing power and storage capacity to ensure the convenience of mobile devices such as smart phones to access the cloud. Learners can freely choose the learning content and learning methods according to the course progress and personal learning needs. The teaching content is generated based on the teaching objectives. It constructs the learning knowledge into a knowledge tree and adopts the rubric. Methods the knowledge content was divided into different levels. Learning from the combination of game based learning and MOOC, the teaching content should also measure the technical requirements brought by mobile device teaching, which is convenient and easy to use in teaching practice, so it is necessary to tailor the appropriate teaching content module. In teaching design, we should pay attention to achieve the corresponding teaching objectives with fewer steps. Combined with the characteristics of the audience groups that the learners of preschool education major in Distance Education ultimately face, it is necessary to grasp the length of the game learning, avoid the learners from indulging in it and breaking away from the teaching objectives, and at the same time, make full use of the game components and mechanisms in the game learning links or steps to enhance the learners' experience and experience of game based teaching, and acquire knowledge in game based scenes. Based on Gardner's multiple cognitive theory, give full play to the advantages of natural cognition, relational cognition, language cognition, emotional cognition, music cognition in smart mobile classroom [12-13]. For example, add game points, badges, leaderboards and other settings in the game based learning component, and add the dynamic mechanism between the emotion, progress, and relationship between the game and people, so as to improve the learners' understanding and feelings for learning. From the point of view of learners, the identification of game learning is often started from the aesthetic design of games, and then from the teaching content and teaching design of game learning to the teaching experience of all aspects of perceiving the fun of game learning, so as to achieve the purpose of smart classroom movement of game learning. Figure 1 shows the design framework of smart mobile classroom.

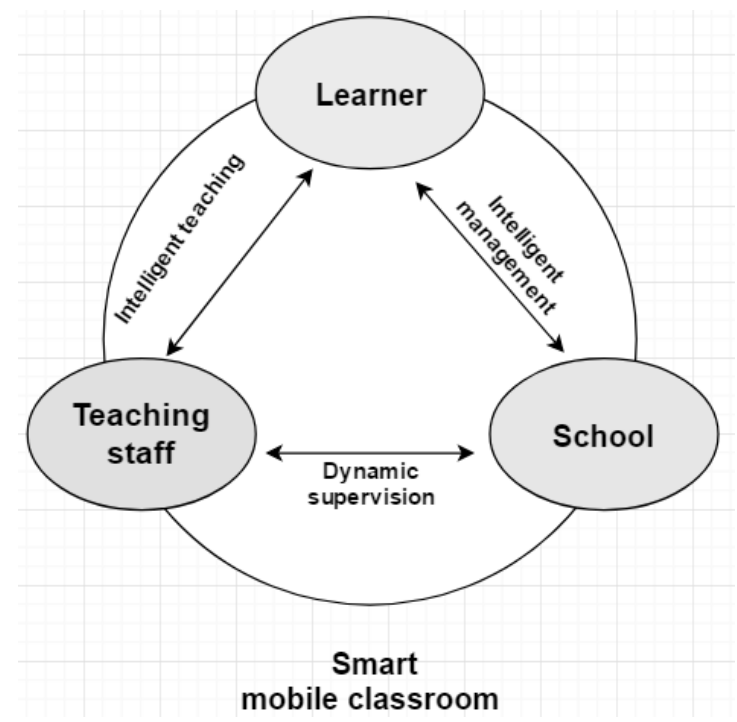

Figure 1. Design framework of smart mobile classroom in the perspective of game based learning.

\subsection{Smart Mobile Classroom Design Practice in the Perspective of Game Learning}

As we all know, interest driven learning is an activity to stimulate learners' learning creativity, so is game based learning. From the perspective of game learning, smart mobile classroom design is particularly suitable for distance education pre-school education learners. For distance education students, the implementation of smart mobile 
course teaching is naturally professional selective, and pre-school education students need to guess the natural learning needs and learning characteristics of pre-school children to carry out practical teaching activities, and game learning is the most natural learning method for pre-school children. The following takes the preschool education major of distance education as an example to illustrate the teaching implementation process of the classroom design from the perspective of learners.

Taking the pre-school English natural spelling course of distance education as an example, the course mainly includes three parts: "learn from me", "do with me" and "do by yourself". Before class, the teaching staff will release the teaching objectives, teaching contents and other materials through mobile devices, so that learners can preview in advance. In the "learn from me" phase, learners use mobile devices to connect to the school wireless network, and the on-demand video 1 starts natural cognition. Around the story of Tom, the protagonist, shopping for vegetables on the street, the video links up 10 words that need to be mastered in this lesson. In the video, Tom and others talk to each other, so as to guide the learners to understand the words in the natural cognitive stage, infer the basic meaning of the single word through the dialogue before and after, and use mobile devices to realize the choice of word interpretation. After 10 groups of words are correctly selected for interpretation, they will be promoted to the music song cognition link. Through video 2 -a group of music songs, these words will be repeatedly displayed to strengthen the learners' cognition. In the "do it with me" phase, learners use mobile devices to simulate Tom's behavior in Video 1, and realize force feedback through gravity sensing, sensors and other technologies, such as using mobile devices to complete an action of putting into a basket according to the prompts, deepening the understanding of these words and their meanings, and realizing body motion perception. Complete all the actions of "do with me" sections, and realize the promotion of the game into the "do it yourself" section. In this part, the camera is used to import the learners' head image into the hero's head image in Video 1, forming a virtual reality situation to carry out the "do it yourself" operation, and finally generate video 3 .

The whole classroom is designed based on the learning situation of preschool children. The operation of teaching mobile devices is easy to use. In the process, game promotion is adopted to encourage learners to further study. At the same time, in the "do with me" and "do by yourself" sections, the cognition of emotion and relationship is added, which enables learners to realize the teaching goal step by step from the beginning of natural cognition, music cognition, language cognition, body movement, to the later of emotional cognition and relationship cognition.

\subsection{Practical Effect Analysis of Smart Mobile Classroom Design in the Perspective of Game Learning}

According to the research before and after the design of smart mobile classroom based on game learning, the course practice effect of time allocation, completion rate of game learning completed within the specified time and feedback of learners is obvious, which significantly changes the low participation of distance education. In the process of time allocation of distance education courses, for example, the average time to complete 10 basic training groups "follow me" has increased from the original $5.67 \mathrm{~m}$ to $13.54 \mathrm{~m}$. For example, the completion rate of "do it yourself" has increased from $75 \%$ to $91 \%$. In the feedback part of learners, learners generally think that this kind of curriculum design makes everyone's enthusiasm for participation improve. Before using the smart mobile classroom design of game based learning, $17 \%$ of the learners thought that there was no harvest or no obvious harvest when they participated in the preschool education related courses of distance education, and $83 \%$ felt that they had some harvest. After adopting the smart mobile classroom design of game based learning, the learners have a high degree of recognition for the classroom design. $96 \%$ of the learners think that they have a big harvest, only $4 \%$ of the learners think that the harvest is not big. In the smart mobile classroom, through the promotion of game based thinking, experience centered, to provide learners with rich and immersive learning experience, which is conducive to the improvement of students' participation, enthusiasm, enthusiasm and efficiency in the classroom, so as to improve the learning effect [14-15]. In general, the expected goal of classroom design has been achieved.

\section{Conclusion}

This paper proposes a feasible way to design the framework of smart mobile classroom in the view of game, and takes the English natural spelling course of distance education as an example to realize the framework. Through the after-school investigation, it shows that it has certain effectiveness in reducing the low participation in distance education, and also finds relevant limitations. First, from the perspective of educational technology, the requirements for the game function are improved, and the module development of the game function of related courses needs to rely on the technical developers. Second, the essence of game learning is learning, so we need to jump out of the game peripheral settings and strengthen the teaching design of other links besides the game. Third, the research of Gamification learning in smart mobile classroom is still in progress. In order to further expand the research of Gamification learning, we need to strengthen the accumulation and research of data, from which we can analyze the deep relationship between Gamification learning and smart mobile classroom, find out the key factors that stimulate learners' interest in learning, and promote the wide application of Gamification learning in the field of education.

\section{Fund Project}

This paper is the research results of "Research on cloud based mobile learning mode" (Project No. : G14A1610w) commissioned by the Open University of China, "Research on the construction of smart mobile learning classroom" (Project 
No.: 2018SCG260) planned by Zhejiang Education Science Planning project, and "Research on the construction of smart classroom in 5G perspective" (Project No.: XKT-QN011) planned by scientific research project of Zhejiang Radio and Television University.

\section{References}

[1] Yang Lan, Zeng Haijun, Gao Buyun. Intelligent learning environment based on cloud computing [J]. Modern education technology, 2018 (11): 26-32.

[2] Sun Shuhui, Liu Bangqi, Li Xinyi. Construction and application of smart classroom in the era of big data [J]. China information technology education, 2015 (z1): 112-114.

[3] Bruce Joyce, Martha Weill and Emily Calhoun. Teaching mode (7th Edition) [M]. Beijing: China Renmin University Press, 2014.

[4] Biran. Challenges and Countermeasures of College Teachers\&apos; professional competence in the context of "Internet + Classroom" [J]. modern education management, 2015, (12): 5.-55.

[5] Liu Bangqi. Internet + era wisdom classroom teaching design and Implementation Strategy Research [J]. China audio visual education, 2016, (10): 51-56.

[6] Bian Jinjin, Xu Fuyin. Study on the design and effect of learning mode based on smart classroom [J]. China audio visual education, 2016, (2): 64-68.
[7] Chen Li, Lin Shi, Zheng Qinhua. Opportunities and challenges of distance education in China in the era of "Internet + " [J]. modern distance education research, 2016, (1): 3-10.

[8] Cui Zhijue. Towards multi Governance: "Internet + Classroom" Teaching Reform [J]. Primary and secondary school management, 2016, (7): 11-13.

[9] Chen Kang, Zhu Yanping, Luo Yu. The design of flipped classroom teaching under the background of "Internet +" -Taking the teaching of international business documents as an example, [J]. foreign trade, 2016, (7): 153-155.

[10] Guo Xiaoshan, Zheng Xudong, Yang Xianmin. Conceptual framework and pattern design of intelligent learning [J]. Modern education technology, 2014, (8): 5-12.

[11] He Kekang, Lin junfen, Zhang Wenlan. Teaching system design [M]. Beijing: Higher Education Press, 2006:81. [10]

[12] Huang Ronghuai. Three realms of intelligent education: from environment, mode to system [J]. Modern distance education research, 2014, (6).

[13] He Mengjie. Based on "Internet +" university classroom teaching big data to explore [J]. modern education management, 2016, (10): 103-107.

[14] Xu Hao, Huang Lan, song Donglei, Yu Tao, Xiao Meng. Intelligent Classroom: Exploration and practice of intelligent and game based Teaching [J]. Computer education, 2017 (6): $10-13$.

[15] Zhu zhiting, Peng Hongchao. Smart learning ecology: a systematic methodology for cultivating smart talents [J]. Audio visual education research, 2017 (4): 5-14. 